\title{
Reimagining Aid for the Next Ten Years: What do Donors Think?
}

\author{
Sara J. Wolcott and Lawrence Haddad
}

\begin{abstract}
This article reports on a workshop facilitated by IDS for representatives of six European development donor agencies. The aim was to create some space for reflection on how aid agencies will need to adapt to, and influence, the changes in the external environment over the next ten years. We identified three key aims for development assistance: narrow national interest, the achievement of the Millennium Development Goals and sustainable global management. The trade-offs and overlaps between these three aims were explored and their implications for the approach, form, capacities and accountabilities of future development agencies were outlined. The authors observed that the space for reflection was much valued by the participants, and argue that the existence of these spaces will come under increased pressure if the results agenda is not sufficiently innovative.
\end{abstract}

\section{Introduction}

The countdown to the Millennium Development Goals (MDGs) target date of 2015, the rise of new global powers, the global financial crisis and the spur to collective action that climate change provides have generated a demand from official development assistance (ODA) donors for a reimagining of aid (Carbonnier 2010; OECD 2010; Severino and Ray 2009). But what do the donors themselves think?

As part of the Reimagining Development initiative, we invited some key European donor organisations to attend a half-day roundtable, facilitated by IDS, to brainstorm on current and future challenges to development, and the kinds of responses these challenges should elicit in the future provision of development assistance.

The criteria for invitation to the roundtable were: (1) individuals had to be in senior leadership positions within the organisation - we wanted to hear directly from those in key decision-making positions; (2) donors with whom the authors had strong relationships - this was a key variable as we wanted to provide a safe space where discussion could be relatively free;

(3) representatives from the bilateral donor space and the new philanthropy space;

(4) individuals currently in a post and those recently retired - again to provide a more open space for discussion and (5) a practical set of considerations (e.g. whether they were close enough to permit participation). Based on these criteria, ten individuals were invited to attend and six accepted: two who were currently with bilateral donors; two from the OECD DAC; one formerly with a bilateral donor and one currently with a major philanthropic organisation. All participants had an opportunity to comment on an earlier version of this article and all agreed to it being part of public record.

Participants were asked ahead of time, how they wanted to structure the three-hour roundtable. They wanted to focus on: (1) current and emerging drivers of change in the donor space;

(2) competing goals of development and (3) some new ideas for navigating the trade-offs between the multiple objectives of aid. One of the authors chaired the meeting and the other provided additional facilitation. The meeting had no formal presentations, rather it was a discussion around the above three points. Not surprisingly, more questions were raised than answered. This article reveals their perspectives, and many of their questions. This analysis focuses more on the discussion itself than integrating it with the larger literature. 


\section{Drivers of change in the donor space}

This section describes these donors' perceptions about changes in the space in which they work.

\subsection{The need for 'sustainable planetary management and collaboration'}

Climate change was presented as the primary example of the increased need for institutions that can deliver 'sustainable planetary management'. The set of issues around sustainable global planetary management concerns is likely to grow in the next ten years. While climate change was considered the key 'game changer', other critical areas included narcotics, trade, security, and financial flow management, which will all require greater international collaboration and governance. How can current ODA structures evolve to deliver these kinds of global goods?' Where will the extra money come from to help manage these global issues? What happens if promises of new funding do not materialise - is there a Plan B? Who is responsible for ensuring that a Plan B exists?

\subsection{Valuing 'unusual suspects' and reaching out 'beyond aid'}

There was a sense that the capability to spur development has become more distributed and the ODA agencies must operate accordingly, learning from these other sources of funding and expertise, and seeking to influence them where practical. Organisations operating in the ODA bubble are far from an exclusive repository of knowledge on international development. They never were of course, but their strengths and limitations are becoming more obvious as other voices and actors emerge. These include the BRICS, oil-rich states, new philanthropic initiatives (big and small), the private sector and the non-ODA parts of donor governments. These actors think and act differently from traditional aid agencies. They challenge aid agencies to reconsider their own goals and principles - and to reimagine development itself. Organisations specialising in delivery of ODA need to find ways to engage with these new sources of expertise and knowledge because (a) not all will be geared to poverty reduction and (b) they can draw on this knowledge to enhance the impact of ODA.

\subsection{Global power shifts}

The multi-polar world makes global management and aid delivery more complex. The new development actors (ODA related or otherwise) may be less interested in overseas poverty reduction per se; more interested in working bilaterally than multilaterally and more prone to use aid for naked self-interest. Although the use of ODA for self-interest has never disappeared, participants wondered if this might be a return to the 1970s and 1980s. DAC members felt they now had to fight harder to get heard in Africa. As ODA management becomes more complex, aid agencies can attempt to short circuit the complexity - or they can innovate to try to navigate through it. But how can aid agencies, with strict accountability norms, innovate sufficiently to navigate intelligently through the complexity?

\subsection{Competition for resources at home}

With the global financial crisis and other pressures on public funds, some aid ring-fencing is occurring in a few countries, although this is not the norm. However, in ring-fenced places, how strong is the fence? And: Does the fence inadvertently impair the ability to reach out beyond aid?

\subsection{Changes in developing countries}

The face of global poverty is no longer a woman with a baby and a pot of water on her head in a rural village. Africa is becoming increasingly urbanised; health, diet and demographic transitions are happening quickly. We see poverty and wealth stubbornly coexisting in India and Africa, as in Latin America. The existence of widespread but concentrated poverty means ODA can have a potentially large impact on human welfare, but the coexistence of wealth means that the public support for the provision of ODA is weakened.

\section{What are donors working for?}

Discussion of these external challenges quickly crystallised agreement about the need to align the three potentially conflicting goals of aid donors: peace (i.e. conflict prevention, peace building); planet (i.e. sustainable management of global resources) and prosperity (MDGs, growth, poverty and inequality reduction and wellbeing).

The simple model shown in Figure 1 was generated in the discussion as a way to explore the underlying tensions between the People Planet Prosperity (PPP) set of goals. It reflects a Western donor's perspective; other perspectives might look very different. 

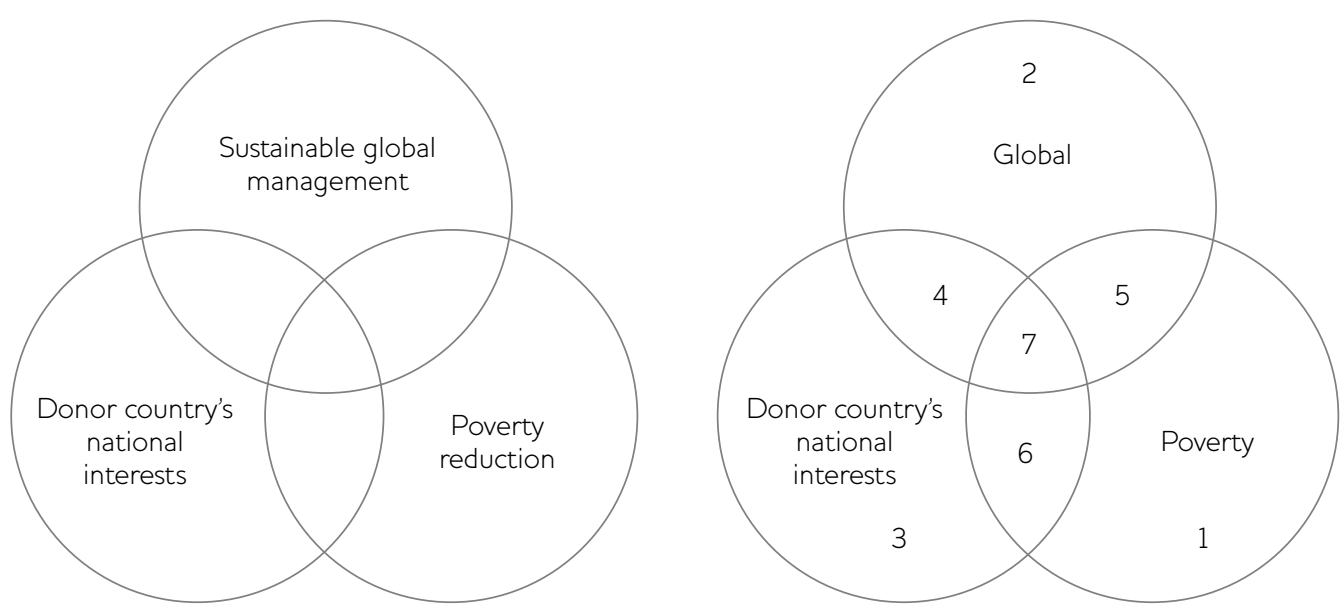

This mapping allows different alignments and non-alignments of these three goals to become clearer, as indicated by areas 1-7. Areas 1-7 were the product of collective analysis, being tidied up after the workshop.

Area 1 indicates the purely moral/values case for poverty reduction. The national interest aim is not strongly represented, nor are goals about sustainable global management. There was a sense that many members of the public in donor countries view international development in this way.

Area 2 represents sustainable global management activities that are not focused on the poorest and which do not seem to be in the immediate donor national interest (e.g. unilateral carbon emission limits in a donor country which may disadvantage donor country industry, but by themselves do not make enough of a difference to change the impacts of climate change on the poorest).

Area 3 describes donor self-interest that does not contribute to global goals and is not poverty- or inequalityreducing (e.g. encouraging carbon-intensive growth that has weak poverty-reducing effects, or using aid to pursue security interests in ways that neither reduce poverty nor add to global security).

Area 4 contains actions that promote national and global interests but not poverty reduction, e.g. cost-efficient green growth, but which are not very poverty reducing or inclusive.

Area 5 represents poverty reduction that reduces instability in the world, but that instability is not perceived to be of immediate national security concern. This could also include environment-poverty initiatives such as communityowned and -operated solar panels in developing countries to generate renewable energy which potentially can be sold in poverty-reducing ways.

Area 6 represents poverty reduction that is perceived to generate national benefits for the donor country. Examples include responsible outsourcing to low-cost labour markets to generate decent work.

Area 7 represents Nirvana. One example is green growth that is pro-poor and for which a donor country has a comparative advantage and uses it responsibly.

One of the greatest areas of uncertainty raised by the participants was the degree to which ODA and agencies specialising in ODA should - or even could - tackle the global management issues, given their limited mandates. They agreed that ODA donors need to maintain the focus on poverty reduction as expressed through the (admittedly imperfect) MDGs. Without this niche, they risk becoming just another global player.
Participants also felt the Venn diagram they generated had important shortcomings. First, there was a sense that different stakeholders would have generated different goals and certainly would interpret the goals differently, find different tradeoffs, and accept different trades. Repeating these exercises with a wider set of stakeholders would help incorporate local knowledge, history and culture into policy formulation and implementation and allow donors to break out of the aid bubble. 


\section{Implications for approach, capacities, form and accountability}

These trade-off and overlap areas outline the key choices ODA donors have to make in the future. We did not have enough time during the roundtable to explore where individual donors would have liked to position themselves and why. But we did identify approaches, capacities, forms and accountabilities that would need to be developed to operate in the overlaps that the above model describes.

On approaches, ventures into the overlaps will inevitably involve ODA agencies being able to function outside of the 'aid bubble'. This means whole of government approaches, whole of society approaches (including building bridges with civil society and the private sector) and making multilateral institutions work better within a world that is not ready for binding global governance rules.

This will require skills such as:

1 A greater ability to facilitate and coordinate larger resource flows towards development. Donors would have to ask themselves, 'would they contribute more effectively to their goal of choice by having 100 per cent control over a small budget or being a 30 per cent shareholder in something much bigger?';

2 A stronger scanning and subsequent response capacity to better anticipate shocks, trends and opportunities (with the accompanying worry of how to scan much wider partner terrains without losing focus and minimising reputational risks);

3 A better ability to value and use knowledge generated from multiple viewpoints to give a 360 perspective on issues;

4 Stronger leveraging of uniqueness of aid (e.g. its focus on poverty reduction, the flexibility of its spend across sectors in country) coupled with a more realistic appraisal of what it can do when operating in isolation.

Finally, the participants wondered how their organisations could develop these new skills without overloading already stretched work programmes?
In terms of exploring different forms of donor agencies, we did not make much progress. We noted three broad ODA organisational models: (1) separate comprehensive ministries (e.g. Germany and UK); (2) location within Ministries of Foreign Affairs with a specialist agency to administer aid (e.g. Sweden, Spain) and (3) as (2) but with no specialist aid agency to administer (e.g. Netherlands, Denmark). It was noted (with surprise) that while there was no good empirical evidence that one set of structures was inherently superior to another, there were some characteristics of successful structures that appeared to be common. So while there was a recognition that business as usual for donors is no longer an option, ${ }^{2}$ there was also little sense of what development agencies should look like in terms of goal, purpose, approach and organisation, either in DAC countries (complicated by whether new funding streams for climate do or do not materialise) or in countries with a comparatively 'clean slate' - for example an emerging donor country such as Poland. There was even some doubt if emerging donor countries should try to follow the same models as current donor countries.

On accountability, it was thought that moving into the overlaps would complicate the balance between different accountabilities (to the donor public, to ODA-dependent publics and to ODAdependent governments). We noted the tensions between these different accountability domains:

Results-based management of ODA may move donors towards service delivery-based aid, and away from the influencing and transformational agendas, unless these risks were explicitly acknowledged and managed;

- Results-based management also runs the risk of trapping aid recipient resources into prioritising accountability to donors rather than to their citizens;

- Can local accountability mechanisms be developed so that ODA fits into a wider range of income sources which are subjected to country-led evaluations for development impact?

- Can accountability be recipient- and citizenled? This would entail strengthening local forces to have the capacity to do so. Could doing so enable greater participation, ownership and perhaps long-term learning? 


\section{So what?}

Participants expressed an interest in future meetings on more specific themes. These included:

- Locating their own agency within the PPP context: where is the donor, where does it want to be located and how should it get from one to the other?

- How can the broken feedback loop in development be fixed? In a more partnerbased series of networks, should partner review and feedback become embedded in results-based management?

- To what extent is the MDG countdown stifling the post-MDG debate on models such as PPP (e.g. Zedillo and Thiam 2006)?

- How to invest in individual and collective efforts to promote donor dialogue on these issues and to share knowledge and learning.

\section{Concluding reflections}

We were not surprised by the excellent capacity of the participants to locate their aid agencies within development and within wider global trends, but we were surprised at their lack of opportunity to have these kinds of informal but structured discussions for reflection, learning and blue-sky thinking.

This analysis suggests that for those working in development, the next ten years will be characterised by increasing uncertainty and the necessity of working with multiple stakeholders and investing in the relationships to do so (Eyben 2006). ODA agencies will have to become more adaptive organisations that can respond to dynamic situations. The recent crises have once again highlighted the importance of building and maintaining this adaptive capacity as a matter of course.

\section{Notes}

1 Zedillo and Thiam (2006) focus on the challenges for nations and the international community, including aid agencies, to attend to global public goods.

2 This, particularly, echoes Deutchser's introductory remarks in Development Co-operation Report 2010 (OEGD 2010).
But the crises have also strengthened the focus of donors on results. This promises to bring many benefits (we all want good change to be spurred on by aid in the most efficient way) but it also brings other opportunities and risks that need to be managed. First, it is possible that the drive to demonstrate impact will drag donors towards the MDG and national interest goals and away from the sustainable global management goals in which impact is harder to show. Second, it is also possible that the results focus will encourage more activity in the overlaps, as more win-win value for money outcomes are sought. Finally, it is possible that the focus on tangible outcomes and getting things done will squeeze out any space for reflection and adjustment.

We did not discuss this in the workshop, but one way of building - even forcing - reflection into donor agency work is to systematically seek feedback from the people the aid is intended to support - citizens in aid-recipient countries. By inviting these stakeholders to hold a mirror up to the donors, donors will get a more rounded and grounded view of their work. One example of this is the Agriculture Learning and Impact Networks (ALINe) programme at IDS. ALINe is currently working with ACDI-VOCA ${ }^{3}$ in the Philippines to evaluate whether the use of mechanisms for generating systematic farmer feedback affects agricultural project manager behaviour and leads to stronger agricultural development outcomes. This is an example of an innovation which might help donors become more adaptive to a changing context. Those of us who work with donors must support them to find other innovations that can them and the rest of us work in this increasingly complex space.

3 ACDI-VOCA is a merger of Agricultural Cooperative Development International/ Volunteers in Overseas Cooperative Assistance. 


\section{References}

Carbonnier, G. (2010) Official Development Assistance Once More Under Fire from Critics, International Development Policy Series, Geneva: Graduate Institute Geneva, http://poldev.revues.org/141 (accessed 5 April 2010)

Eyben, R. (2006) 'Introduction', in R. Eyben (ed.), Relationships for Aid, London: Earthscan

OECD (2010) Development Co-operation Report 2010, OECD Development Assistance Committee (DAC), www.oecd.org/dataoecd/32/24/ 45051632.pdf (accessed 23 April 2010)
Severino, J. and Ray, O. (2009) End of ODA: Death and Rebirth of a Global Public, CGD Working Paper 167, Genter for Global Public Policy, www.cgdev.org/content/publications/detail/ 1421419 (accessed 3 April 2010)

Zedillo, E. and Thiam, T. (2006) International Cooperation in the National Interest, Report of the International Task Force on Global Public Goods, Final Report, Stockholm 